\title{
O alteamento vocálico da pretônica posterior e a relação de estigma e identidade na Amazônia Tocantina
}

\author{
The vocalic raising of the pre-tonic vowel and its relation with the stigma and the \\ Tocantina Amazon identity \\ Benedita Maria do Socorro CAMPOS DE SOUSA*
Universidade Federal do Pará (UFPA)
}

RESUMO: Este artigo objetiva verificar em que medida a existência de estigma veiculada pela ação da escola atua sobre o sujeito sociológico constituído pela relação de identidade amazônica paraense, a partir da verificação da redução de probabilidade de elevação da vogal média [o] em posição pretônica. As análises incidiram sobre o corpus de Correa e Campos (2018), estabelecendo um cotejamento com Rodrigues (2005), o método de análise é quantiqualitativo, utilizou-se o programa estatístico GOLDVARB-X para a contagem das ocorrências sobre as quais discutem-se a temática alteamento, identidade e estigma, subsidiado por Goffman (1975), Hall (2001). Os resultados apontam para a resistência de elevação do [o]>[u] em posição pretônica por extensão da ocorrência na tônica, reconhecidamente estigmatizada. Conclui-se que a escola exerce uma forte influência no sentido de vetar o alteamento da vogal média posterior para fugir do estereótipo de fala interiorana, distanciando o sujeito da sua identidade amazônica.

PALAVRAS-CHAVE: Alteamento. Identidade. Estigma. Amazônia Tocantina.

ABSTRACT: This paper aims to check the extent of the stigma disseminated through the school in the sociological subject constituted by the Tocantina Amazon identity. The investigation start point was the reduction of mid-vowel [o] raising, in pre-tonic position. Correa and Campos (2018) and Rodrigues (2005) corpus were used in this investigation, also a comparison between them was made. The method was quantitative and qualitative and to count the occurrence of the raising, identity, and stigma, subsidized by Goffman (1975) and Hall (2001), the statistic program GOLDVARB-X

\footnotetext{
* Professora Doutora Pela Universidade Federal do Ceará, professora da Faculdade de Linguagem, da Universidade Federal do Pará, Campus Universitário do Tocantins/Cametá-Pará. Email: bmsocorrocampos@gmail.com
} 
was used. The results reveal a resistance in the raising of the $[\mathrm{o}]>[\mathrm{u}]$ in the pre-tonic position, as a consequence of the stigmatized stress. This analysis shows that the school exerts a great influence inhibiting the raising of the posterior mid-vowel, in order to avoid the countryside speech, dissociating the subject from his Amazon identity.

KEYWORDS: Raising. Identity. Stigma. Amazônia Tocantina.

\section{Introdução}

As vogais médias pretônicas têm sido frequentemente objeto de diversos estudos, seja numa perspectiva fonética, fonológica, seja nos prismas da Dialetologia e da Sociolinguística Variacionista, o que demonstra seu grande potencial de realização e, consequentemente, de variação dada à realidade linguística do povo que a fala. Assim, a língua está presente no indivíduo, dele faz parte, por ele se manifesta e o marca.

A língua é manifesta pelo sujeito por seus atos individuais de fala, contudo o sujeito falante não consegue se desvencilhar das influências de sua comunidade, construindo-se no entrelaçamento entre o "eu" e "o(s) outro(s)". No dizer de Hall (2001) o sujeito sociológico surge quando a identidade individual se entrelaça com a identidade de outros, o que ocasiona uma mudança de individualização para a interação, essa ação é recíproca entre sujeito e sociedade, é então, essa identidade que dará suporte para o indivíduo se situar e se sustentar no meio em que vive.

Dessa forma, o indivíduo possui sua própria identidade que pode diferenciá-lo ou identificá-lo com o outro, criando entre o "eu" e o "outro" uma espécie de força de atração e de repulsão (ou rejeição). Assim, a identidade compõe-se de subjetividades, expressa-se por muitas simbologias, dentre estas encontra-se o uso da linguagem. A linguagem identifica o ser falante, demarca seu território; nesse sentido, o falar talvez seja o que mais evidencia a identificação de um indivíduo com o meio do qual faz parte, assim a realização das vogais, parece ser uma marca indelével da sua constituição como sujeito sociológico.

Por essa razão, optamos por um estudo das variações da vogal média posterior localizada em posição pretônica na manifestação linguística da cidade de MocajubaPará. Embasamo-nos na pesquisa de Campos (2008) sobre o alteamento vocálico neste 
município, Correa e Campos (2018), tecemos algumas correlações com Rodrigues (2005). Averiguamos a realização da vogal média /o/>/u/ na área urbana do município estudado, partimos da estratificação em sexo, faixa etária e escolaridade. Para as entrevistas, seguimos o modelo de Labov (1983) de narrativas espontâneas sobre temas diversos como: família, trabalho, política, educação, entre outras.

Por haver necessidade de quantificação dos dados, utilizamos o Programa Computacional GOLDVARB-X. Por meio dele medimos estatisticamente os dados de 48 informantes da área urbana, sendo 24 homens e 24 mulheres. Partimos da variável dependente: presença de alteamento vs ausência de alteamento e para explicá-la servimo-nos das variáveis independentes: escolaridade, faixa etária, sexo (fatores extralinguísticos); quanto aos fatores linguísticos consideramos a influência da vogal contígua, a distância relativa à sílaba tônica; atonicidade; a consoante do onset do fenômeno; consoante do onset da sílaba seguinte.

Por uma necessidade de organização textual, faremos uma breve explanação sobre alteamento, identidade e estigma na Amazônia, sobre procedimentos metodológicos adotados, em seguida, apresentaremos os resultados acompanhados de suas respectivas discussões.

\section{Alteamento, identidade e estigma na Amazônia Tocantina}

A preocupação com a identidade linguística da Microrregião Cametá surge a partir da percepção de que há alguns aspectos da variedade linguística dessa região que a particulariza, dentre eles, a elevação das vogais médias em posição tônica talvez seja a forma mais marcante dessa manifestação linguística, principalmente quando se refere à média posterior, caracterizando o alteamento $/ \mathrm{o} />[\mathrm{u}]$, segundo Rodrigues (2005), atribuída à classe menos favorecida da região:

o alteamento /o/ > [u] no município de Cametá foi uma preocupação com a identidade linguística de comunidades menos favorecidas social, econômica, política e culturalmente, visando ao reconhecimento de seus falantes como usuários de uma variedade do português com características próprias, diferentes, mas em hipótese alguma errada, como durante anos se incutiu ideologicamente entre os habitantes do próprio município (RODRIGUES, 2005, p.21) 
A elevação da vogal média posterior em posição tônica tem sido razão para muitas formas de preconceitos, comentários jocosos e depreciadores do falar do Baixo Tocantins, reações fortemente estigmatizadoras, muitas vezes, dos próprios falantes da região, atribuindo somente aos moradores de Cametá essa marca, contudo sabemos que esse fenômeno já fora documentado na década de 70, quando Silva Neto (1977, p.168) referiu-se à variedade dialetal do interior da Amazônia Paraense como o dialeto da canua cheia de cucos de pupa a prua, como podemos observar no Mapa 01, abaixo, idealizado por Cassique (2005), adaptado por Campos (2008).

\section{Mapa 01: Mapa do Pará destacando as zonas dialetais ${ }^{1}$ nas quais ainda há presença do}

\section{dialeto amazônico}

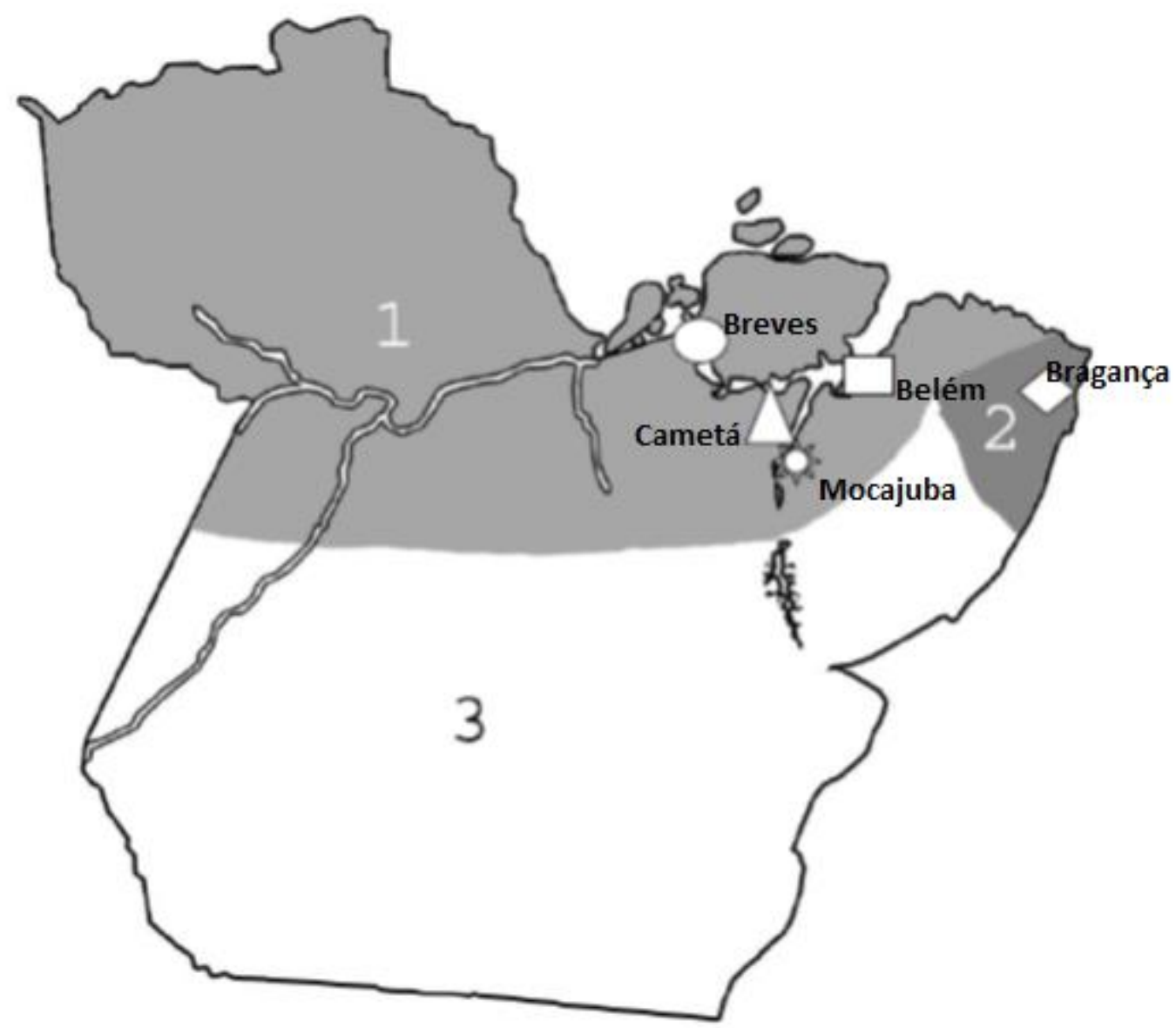

Fonte: Adaptado de Cassique (2005)

\footnotetext{
${ }^{1}$ (1) área denominada canua cheia de cucus de pupa a prua, a mais extensa, que abarca todo o norte do Estado; (2) área "bragantina", a nordeste e ao extremo leste do Estado, especialmente nas áreas urbanas; (3) área do "Sul do Pará", abarcando toda parte setentrional do estado
} 
Se a elevação das vogais médias em posição tônica constitui uma marca da Amazônia interiorana, o mesmo não ocorre em posição pretônica, pois muitas pesquisas demonstram ocorrências em várias partes do país. Contudo, o que temos observado é que há diferentes formas de aceitação do alteamento, pois quando se trata das vogais anteriores, a resistência por parte das pessoas escolarizadas é menor; assim falar m[i]nino, p[i]rigo, p[i]rigoso parece perfeitamente aceitável, sem que haja estigma, a julgar pelas ocorrências em falas de pessoas de escolaridades mais elevadas. Mas, quando se trata das vogais posteriores, há uma aparente resistência, o estigma atribuído à elevação da média posterior na tônica parece se estender à pretônica, evitando por exemplo, $c[u]$ nheci, $c[u]$ ntar, voltando-se para uma pronúncia praticamente artificial como observou Campos (2008), para fugir da elevação /o/ /u/ por considerar uma marca interiorana, de pessoas pouco ou não escolarizadas, muitas vezes, chegam a pronunciar palavras que seriam com $[\mathrm{u}] /[\mathrm{o}]$, como se observa no falar mocajubense "Estou s[o]ando" em vez de "eu estou s[u]ando". Nossa percepção do estigma atribuído à elevação da média posterior em posição tônica, já fora observado também por Cassique (2003):

\begin{abstract}
A condição estigmatizante do comportamento nesse caso é tal que se evita o [u] num contexto linguístico em que o alteamento não é característica dialetal cabocla paraense, mas de diversas áreas brasileiras, inclusive metropolitanas. O fato não implica uma atitude reflexiva sobre a língua e seu uso, mas um auto-monitoramento do falante, presidido pela norma padrão escolar, que ele treinou, em que a forma eleita evita que a variável, depende em causa neste trabalho se manifeste pelo [u]. (CASSIQUE, 2003, p.104)
\end{abstract}

Assim, podemos dialogar com Goffman (1975) que a carga de significados atribuídos a características que diferenciam o olhar por um determinado fenômeno é construída socialmente, desta forma, uma característica pode ser vista como um estigma ou confirmação de normalidade, a depender da sociedade na qual o indivíduo se encontra. Considerando essa forma de percepção, diríamos que a elevação da vogal média posterior em posição pretônica, na Amazônia Tocantina, demonstrada pela ação da escolaridade, é "um tipo especial de relação entre atributo e conceito, embora se 
proponha a modificação desse conceito, em parte porque há importantes atributos que em quase toda a nossa sociedade levam ao descrédito". (GOFFMAN, 1975).

O descrédito da elevação vocálica em posição tônica é atribuído à camada economicamente desprestigiada, interiorana, cabocla, desprovida de formação escolar, discriminada, portanto, em vários setores sociais, como se pode constatar na fala de Rodrigues (2005).

Os dados do português falado em Cametá me dizem que, a partir da relação entre o fator escolaridade e procedência, o alteamento $/ \mathrm{o} / \mathrm{\textrm {u }}$ ] é fenômeno de maior proeminência na fala de analfabetos da zona rural, haja vista 480 realizações, percentual de $76 \%$, de um universo de $\mathbf{6 2 9}$ dados decorrentes do cruzamento entre esses dois elementos de grupos de fatores, diminuindo sua ocorrência entre os analfabetos da zona urbana, considerando que, de $\mathbf{7 2 0}$ dados resultantes desse cruzamento, apenas $\mathbf{4 3 5}$ ocorrências, percentual de $60 \%$, manifestam o fenômeno em estudo. (RODRIGUES, 2005, 143).

É a marca de diferenciação social que faz um sujeito sociológico afastar de si aqueles que não se sentem seus iguais, que com ele não se identificam.

\section{Materiais e Métodos}

A identidade linguística dos sujeitos sociológicos aqui estudada se constrói primordialmente na zona urbana da cidade de Mocajuba, no nordeste do Pará, uma cidade ribeirinha, que faz parte da região do Baixo Tocantins. Ao norte, avizinha-se a Cametá-Pará, município de acentuadas marcas linguísticas identitárias conforme pesquisas de Cassique (2001), Rodrigues (2005), Campos (2008). A comunidade mocajubense se distancia a $244 \mathrm{~km}$ da capital paraense e os sujeitos desse lugar interagem frequentemente com os de Cametá por necessidade de realização de serviços bancários, previdenciários, comerciais e outros.

Dada a dinâmica do transporte rodoviário dos últimos anos, Mocajuba encontrase integrada aos municípios limítrofes de Baião (ao Sul), Igarapé Miri (ao Norte), a Moju, (a Leste). Além de Cametá, cuja integração maior é pelo rio Tocantins. Essa integração entre os municípios do Baixo Tocantins favorece a aproximação das formas linguísticas utilizadas nessa região. A escola como parte da construção do sujeito apresenta baixo índice de desenvolvimento pelas avaliações institucionais, como o 
IDEB. Para representar essa comunidade, entrevistamos 48 sujeitos construídos pela relação de identidade com esse município, sendo 24 homens e 24 mulheres, pertencentes a quatro grupos de formação: os não escolarizados, escolarizados de ensino fundamental, do ensino médio e do ensino superior.

A coleta de dados foi realizada predominantemente nas residências dos sujeitos, tentando criar um ambiente de espontaneidade para evitar artificialidades nos seus pronunciamentos diante da presença do gravador, após gravados os áudios das interações realizadas por meio de entrevistas sobre temas cotidianos, políticos, modo de vida, entre outros, ouvimos exaustivamente os áudios e deles abstraímos os grupos de força, com as ocorrências da vogal média posterior em posição pretônica, para alimentar o programa estatístico GOLDVARB-X que nos forneceu as informações quantitativas para construirmos nossas análises e conjecturas sobre a manifestação linguística mocajubense face aos demais falares da Amazônia Tocantina.

Como já mencionado, este é um estudo quanti-qualitativo, pois parte de dados numéricos que serviram de parâmetros para analisarmos as ocorrências do fenômeno estudado, é de natureza indutivo, pois, a partir das quantificações correlacionamos conceitos sobre a identidade do sujeito sociológico amazônico para abstrairmos sua construção como ser falante de uma determinada variedade linguística. Para chegarmos a essas conjecturas, tomamos variáveis dependentes (presença de alteamento vs ausência de alteamento); variáveis independentes, subdivididas em dois grupos: linguísticas e não linguísticas.

As variáveis linguísticas estudadas foram (1) a vogal contígua; (2) a distância relativa à sílaba tônica; (3) a atonicidade; (4) a consoante do onset do fenômeno; (5) a consoante do onset da sílaba seguinte. As variáveis não linguísticas consideradas como forma de caracterização do sujeito falante foram (1) sexo; (2) escolaridade (3) faixa etária.

Dentre as variáveis linguísticas selecionadas para este estudo três foram consideradas mais relevantes pelo programa (como veremos nas análises), contudo as variáveis não linguísticas nos mostraram muito sobre a construção da identidade do sujeito falante da Amazônia Tocantina, como veremos na seção sobre resultados, análises e discussões. 


\section{Resultados, análises e discussões}

Iniciamos as análises pela variável dependente, para a qual encontramos 2.223 dados; desses 1.139 representam a presença de alteamento e 1.084 a ausência dele. Colhidos a representantes nativos da variação linguística do município de MocajubaPará, convidados a participar de uma interação verbal sobre experiências de vida, fatos cotidianos, conhecimentos do seu lugar de origem, entre outros assuntos que porventura sentissem vontade de expressar, a despeito das imposições que a presença do gravador pode causar, como o paradoxo do observador dito por Labov(1983).

Com base nos dados estatísticos fornecidos pelo Programa Goldvarb-X, observamos a ocorrência do alteamento na vogal média posterior, como discorreremos abaixo:

Gráfico 01: Percentuais do Processo de Alteamento da Vogal média posterior [o] no município de Mocajuba.

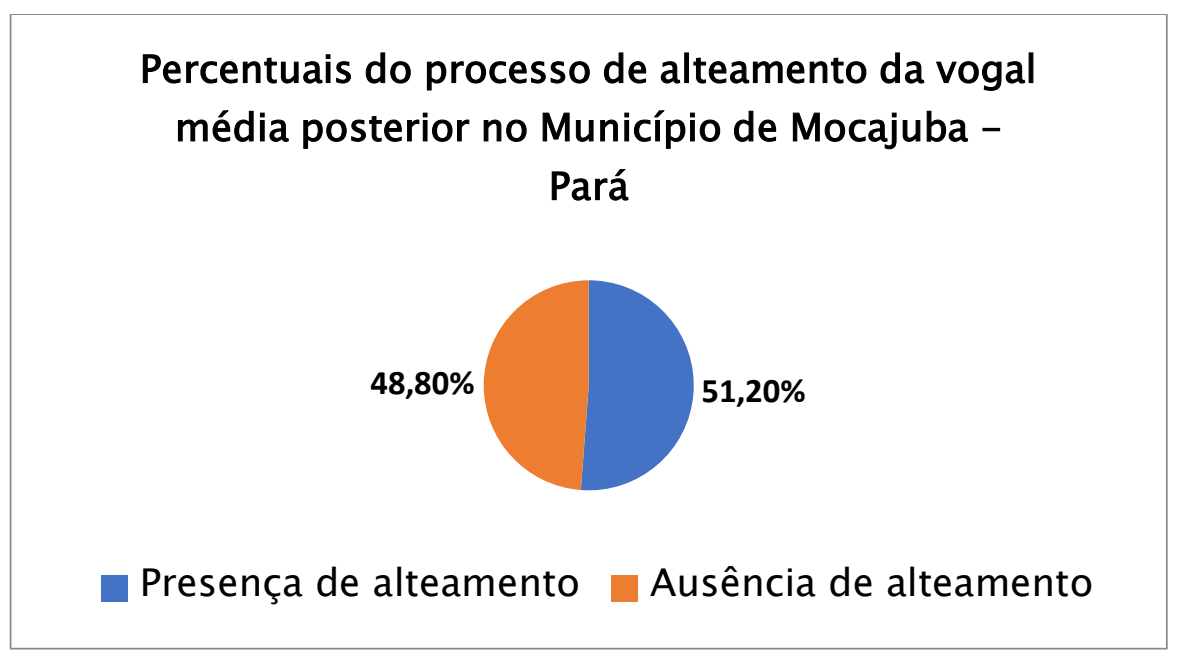

Fonte: Correa e Campos (2018)

Partindo do gráfico 01 obtido dos dados coletados, observamos que a possiblidade de [o] ser pronunciada como [u] superou a de ser mantida como [o], o que contradiz os dados de Campos (2008) em que a possibilidade de manutenção era maior do que a de alteamento, embora a diferença seja mínima, pois há um 
contrabalanceamento em que a ausência de alteamento é de $51 \%$ e de presença é de $49 \%$, constatando que temos um fenômeno em variação estável. Pois se estabelecermos um cotejamento entre os dados de Campos (2008) e de Correa e Campos (2018), veremos que há uma compreensão de estabilidade no sistema de variação. Na percepção de Correa e Campos (2018), a ocorrência de alteamento na zona urbana do Município de Mocajuba-Pará, confirma a tendência de outras cidades do nordeste paraense, como Breves $^{2}$ e Cametá ${ }^{3}$.

Contudo, quando optamos por fazer uma nova verificação sobre o alteamento da vogal média posterior em posição pretônica, pretendíamos elucidar o fato de que a 'rejeição' do [u] em posição tônica na Amazônia Tocantina, pelos escolarizados, seria estendida à posição pretônica. Diante do cômputo geral, atribuído por Campos (2008) em que a ausência de elevação foi de $51 \%$ e de presença de $49 \%$ e de Correa e Campos (2018) foi de $51,2 \%$ para a presença de alteamento e $48,8 \%$ para a manutenção da vogal média posterior pretônica, temos parâmetros muito próximos estatisticamente aceitáveis pela "margem de erro" ou de variação, apontando uma relação de neutralidade para a elevação ou sua manutenção. Cabe então verificar em que medida a escolaridade atua sobre esse processo de elevação das vogais.

\subsection{Influências de variáveis linguísticas}

Tecendo rápidas considerações sobre as motivações linguísticas, constatamos algumas variáveis importantes para a explicação da presença de elevação: a influência da vogal contígua, a consoante do onset do fenômeno, a consoante do onset da sílaba seguinte à da ocorrência do fenômeno. Estes fatores foram selecionados pelo programa como favorecedores de elevação da média posterior na zona urbana do município de Mocajuba-Pará.

a) A vogal contígua

O gráfico 02 , abaixo, sintetiza os resultados da ação da vogal contígua à do fenômeno em estudo. Vejamos o que nos dizem os dados:

\footnotetext{
${ }^{2}$ Cassique (2001);

${ }^{3}$ Araújo e Rodrigues (2007); Rodrigues (2005)
} 
Gráfico 02: Porcentagem referentes à ocorrência do alteamento do [o] no português falado no município de Mocajuba, considerando a vogal contígua à vogal estudada.

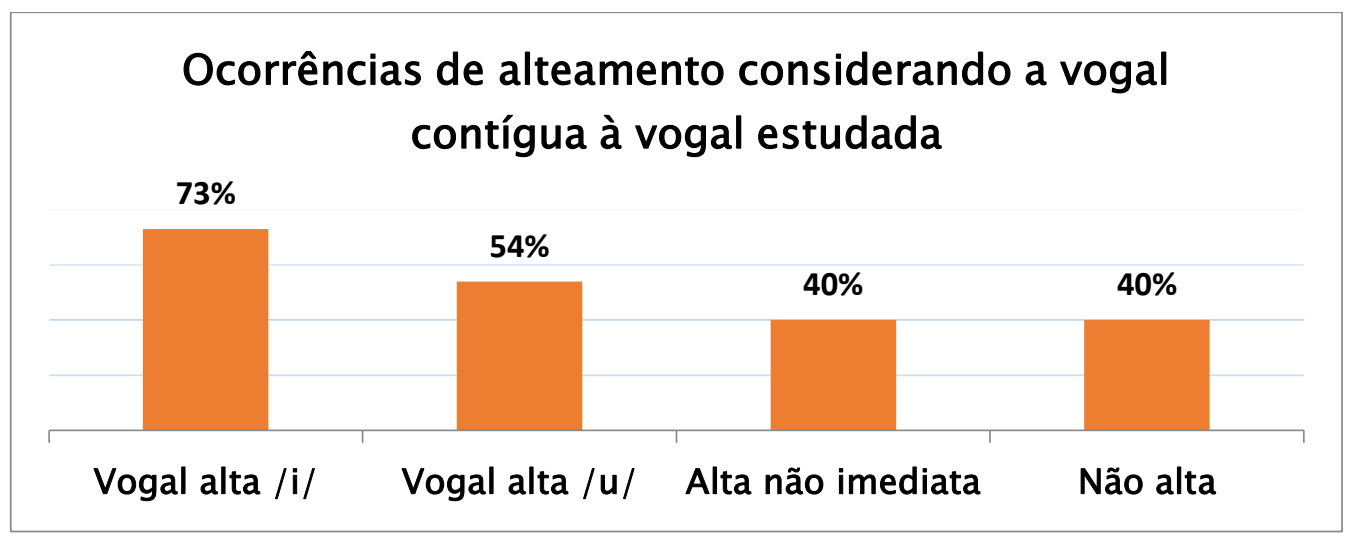

Fonte: Elaboração Própria

Constata-se como em Dias et al (2008); Araújo e Rodrigues (2007); Campos (2008) a forte ação das vogais altas sobre as médias para a ocorrência do alteamento, de modo que as vogais altas /i/ e /u/ parecem 'alçar' a média /o/, trazendo-a para sua altura, buscando uma harmonização na pronúncia das palavras, deixando seus órgãos articuladores mais confortáveis.

b) Consoante do onset

O gráfico abaixo, 03, sintetiza os dados referentes à consoante presente no onset ou a ausência dela. Optamos por dividir as consoantes em grupos de acordo com suas peculiaridades, assim, temos: as coronais, dorsais, labiais e os onsets vazios e os ramificados. 
Gráfico 03: Percentuais de ocorrências de alteamento em relação ao onset da pretônica [o] no município de Mocajuba-Pará

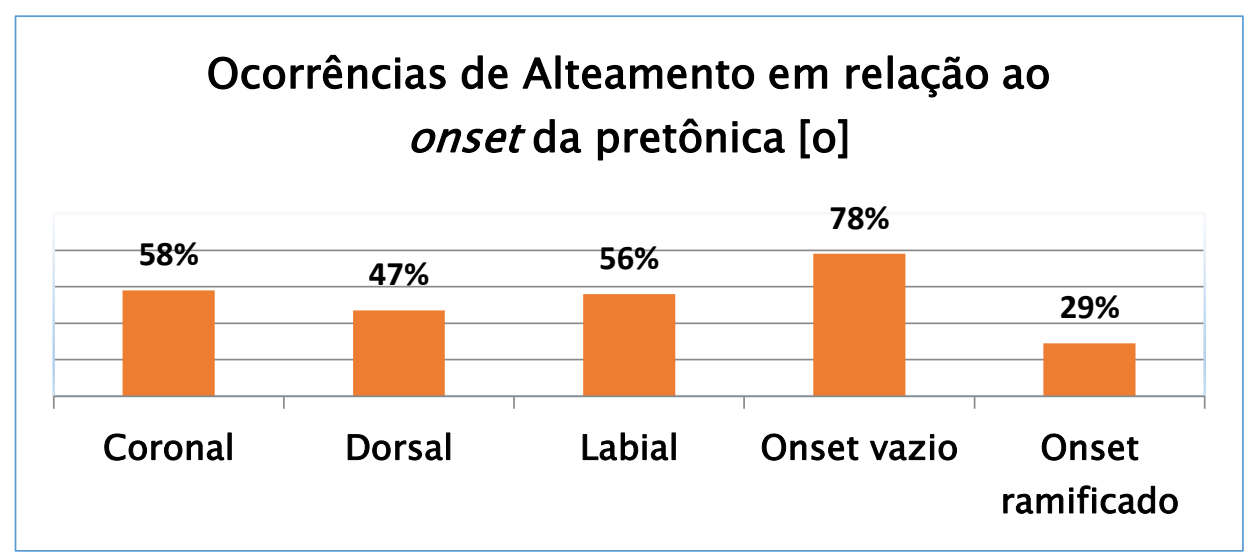

Fonte: Elaboração Própria

Primeiramente podemos observar que a ausência da consoante é um fator altamente influenciador da elevação da vogal em estudo, corroborando pesquisas como de Araújo e Rodrigues (2006), Dias et al (2007), Campos (2008). O onset ramificado foi o que mostrou melhor potencial influenciador de elevação nesta pesquisa. Já nos onsets que apresentaram as consoantes, vemos a influência das coronais e das labiais muito próximas, mostrando possibilidades quase idênticas de motivação do alteamento da vogal média posterior.

c) Consoante do onset da sílaba seguinte

Os dados aqui registrados por meio do gráfico 04, abaixo, tal como o anterior, referente ao onset do fenômeno estudado, mostram que o onset vazio da sílaba seguinte também possui um caráter motivador do fenômeno do alteamento vocálico da vogal em posição pretônica, destacando-se significativamente dos outros motivadores. Entre as consoantes presentes no onset silábico foram as labiais as que impulsionaram o alteamento. 
Gráfico 04: Percentuais de ocorrências de alteamento em relação ao onset da sílaba seguinte à pretônica [o] no município de Mocajuba-Pará

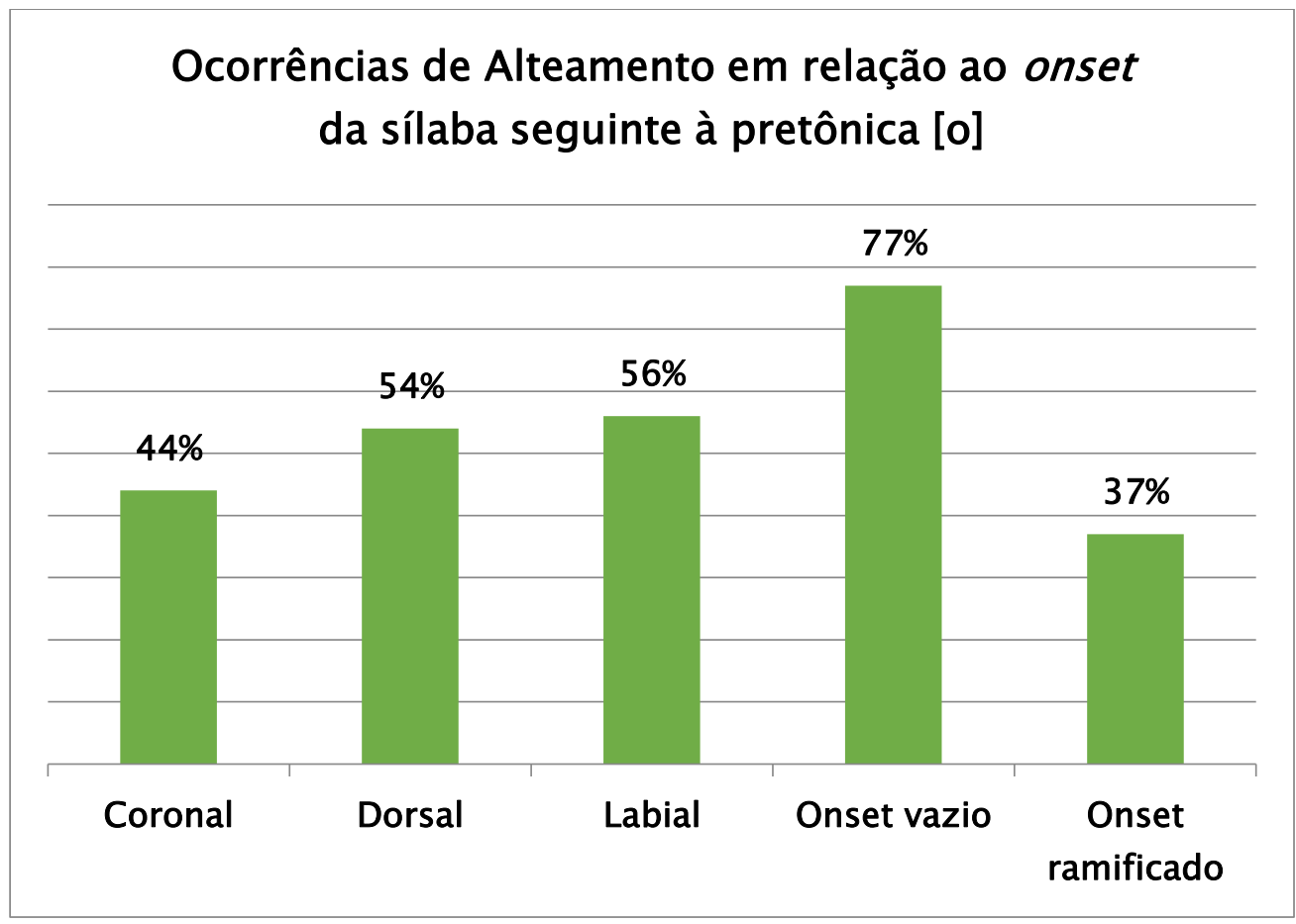

Fonte: Elaboração Própria

\subsection{Influências não linguísticas}

O presente artigo que busca refletir sobre a relação de estigma e identidade, tomando como fato mais concreto o alteamento vocálico, não pode deixar de considerar as influências extralinguísticas para explicar as correlações existentes entre o fenômeno e os sujeitos que o realizam. O mesmo sujeito sociológico a que já nos referimos que se constitui no entrelaçamento da identidade dos outros. É a identidade amazônica de construir um sujeito que ora renega suas marcas linguísticas pelos mecanismos de controle do estado, como a escola; ora em uma vertigem de liberdade expressa sua naturalidade e deixa a identidade vir à tona. Para tal discussão, selecionamos três fatores primordiais: sexo, escolaridade e faixa etária. 
a) Sexo do sujeito da pesquisa

Se o sujeito sociológico se constrói na relação com os outros, em que o 'eu' só existe porque existe um 'tu' e vice-versa, o gênero na sua pós-modernidade ainda aponta para uma diferença de manifestação linguística, assim polarizados em homens e mulheres, verificamos uma diferença percentual que aponta que os homens optam pelo uso da variedade inovadora enquanto a mulher mantém maior formalidade, conservando a vogal média posterior [o]. Parece-nos, então, o homem mais próximo da sua identidade regional, menos preso às convenções das instituições normalizadoras e menos preocupado com a visão estigmatizadora, se considerarmos que o alteamento na vogal posterior em posição pretônica é evitado por extensão ao estigma que opera sobre a tônica.

Gráfico 05: Percentuais de ocorrências de alteamento da vogal média posterior [o] por sexo

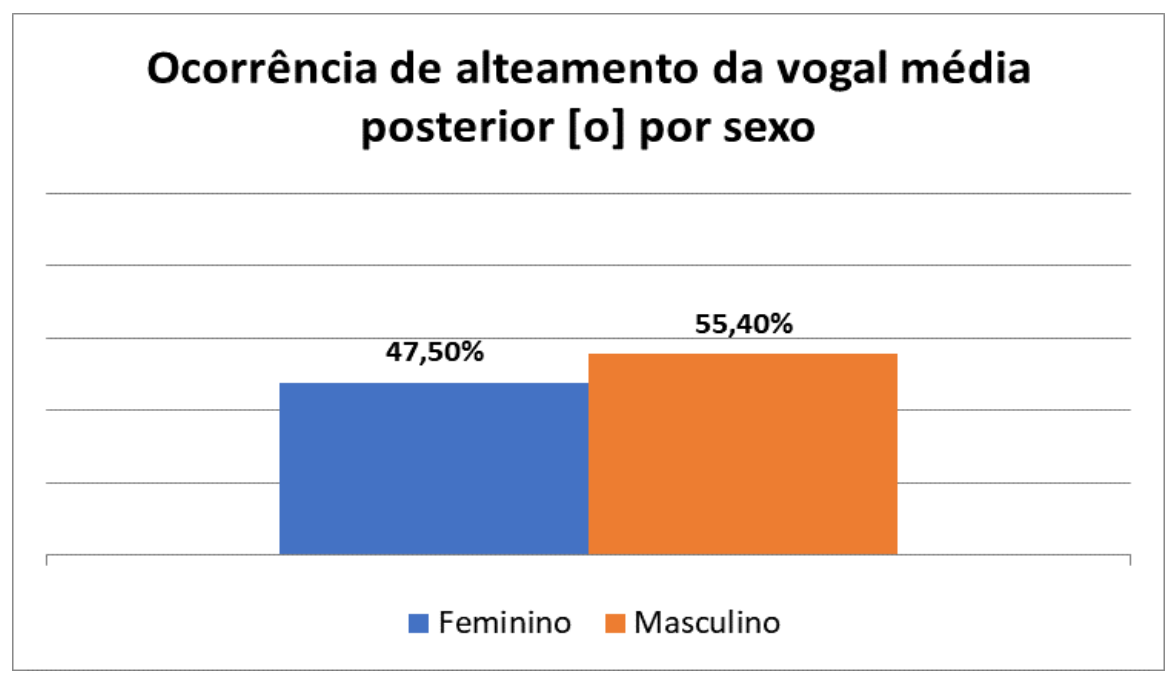

Fonte: Elaboração Própria

b) Faixa etária

Outro fator considerado sobre o sujeito da pesquisa é a faixa etária. Considerando três faixas, observamos que a elevação da vogal média posterior é bem 
maior entre as pessoas que possuem mais de 45 anos, o que significa o distanciamento da ação da escola. São pessoas que se constituíram sujeitos provincianos, enquanto o município ainda possuía menos influências externas, o transporte e os meios de comunicação eram rarefeitos, muitos deles ainda mantêm viva a imagem da vivência ribeirinha, de um tempo lento, de um modo de vida tranquilo da cidadezinha do interior. Por outro lado, quanto mais jovens, mais se afastam do alteamento, talvez levados pela forte ação da escola, dos textos, dos aplicativos de mensagens e de um modo de vida que exige maior celeridade.

\section{Gráfico 06: Porcentagens referentes à ocorrência do alteamento do [o] no português} falado no município de Mocajuba, considerando a faixa etária do informante.

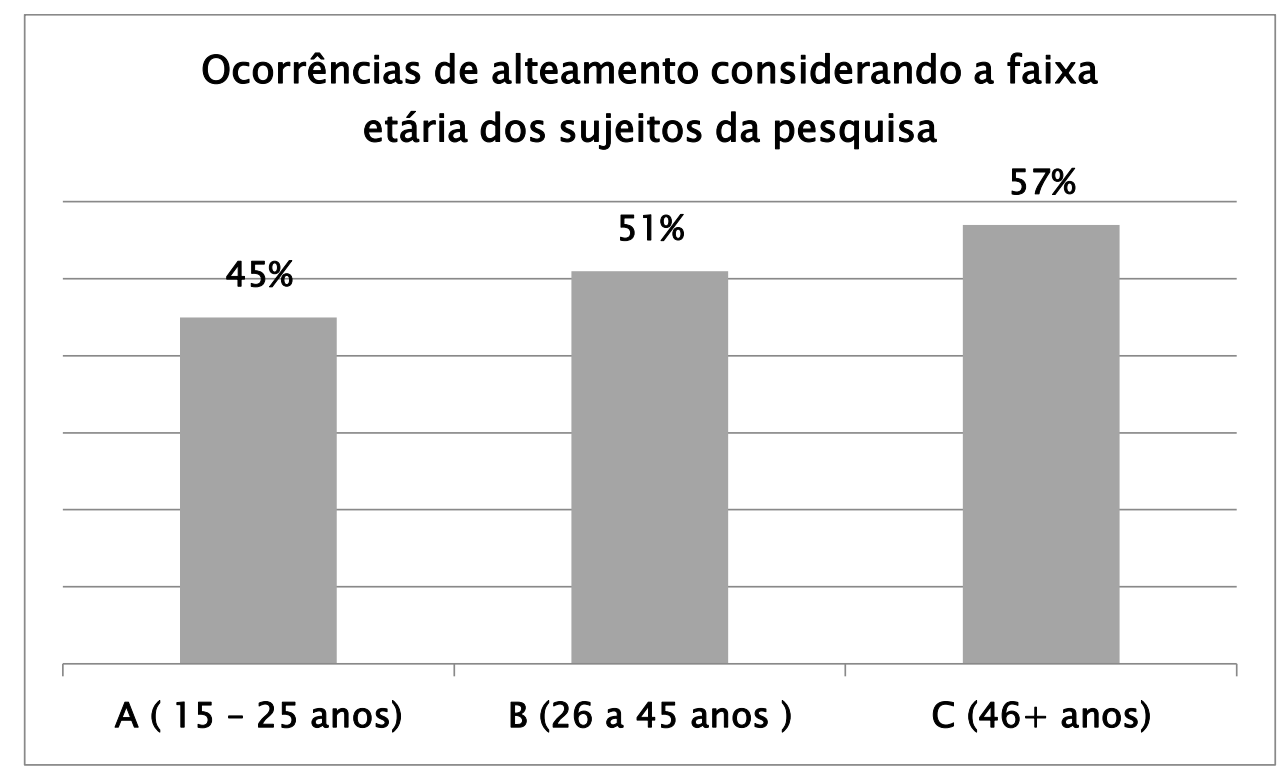

Fonte: Elaboração Própria

c) Escolaridade

Diante dos dados de escolaridade, percebemos que à medida que a escolaridade aumenta, diminui a elevação da vogal média pretônica posterior, se diminui a escolaridade, o alteamento está mais presente, constituindo uma relação inversamente proporcional, como podemos constatar no gráfico abaixo: 
Gráfico 07: Percentuais referentes à ocorrência do alteamento do [o] no português falado no município de Mocajuba, considerando a escolaridade do informante.

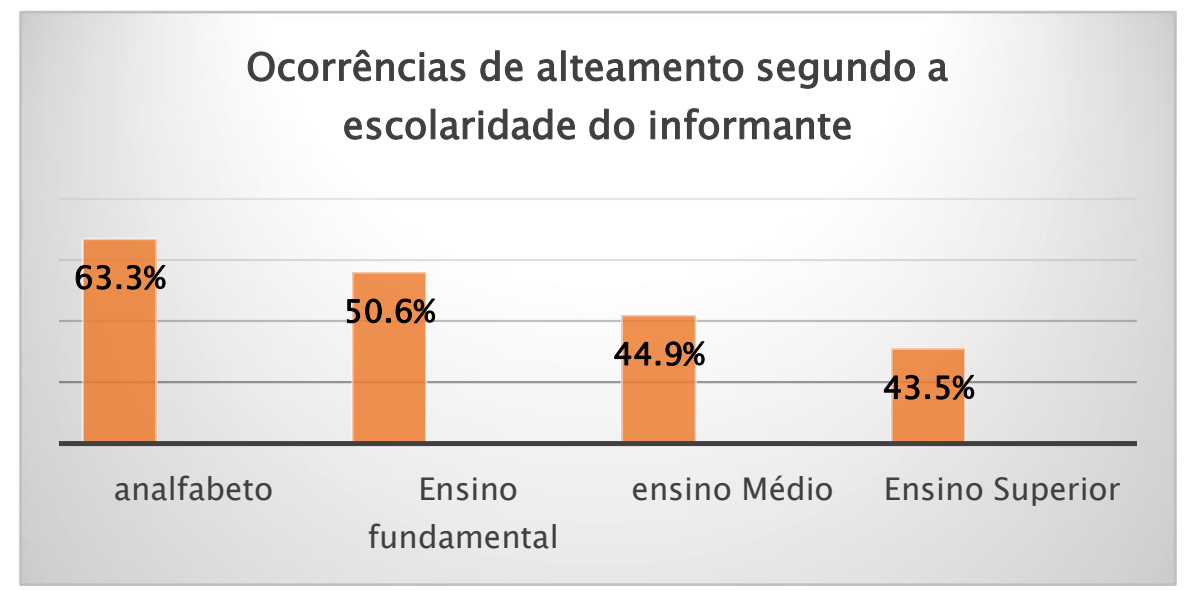

Fonte: Correa e Campos (2018)

Diante desses dados, fica clara a ação da escola de vetar o fenômeno alteamento, assim como se clarifica a presença de estigma diante da elevação da vogal média posterior em posição pretônica (que não constitui marca dialetal da Amazônia), quando se trata de uma subida para $[\mathrm{u}]$, o falante parece monitorar-se e a escola age no sentido de vetá-lo, em virtude de ser processo semelhante ao que se dá em posição tônica $t[u] c u$, b[u]ca, fenômeno comprovadamente estigmatizado, segundo Cassique (2001) e Rodrigues (2005).

\section{Conclusão}

O presente artigo apresenta uma breve reflexão sobre a ocorrência do alteamento na Amazônia Tocantina, confrontando essa marca identitária dos sujeitos sociológicos que se constroem no modo de vida ribeirinho com a noção de estigma presente sobre esse fenômeno. A presença de alteamento na tônica que parece estar em vias de apagamento (RODRIGUES, 2005) por ser claramente estigmatizada, encontra forte resistência na escola por ser a língua do caboclo amazônico desprovido de formação escolar, considerada pela escola como desagradável aos ouvidos. 
A partir dos dados verificamos que a presença de alteamento da vogal posterior superou a sua ausência, embora os indicativos numéricos sejam muito próximos. As variáveis linguísticas consideradas relevantes para explicar a elevação da altura da vogal $[\mathrm{o}]>[\mathrm{u}]$, foram a influência da vogal vizinha, especialmente as vogais altas, o onset vazio e a influência de algumas consoantes, especialmente as labiais. Como nossa pretensão está mais voltada para a ação da escola sobre o comportamento do sujeito diante da realização da vogal média posterior, atentamos para a escolaridade e mais dois fatores extralinguísticos que acreditamos subsidiarão na melhor compreensão da relação alteamento, identidade e estigma.

Os dados de escolaridade vêm confirmar que as instituições escolares possuem uma influência significativa no papel da elevação da vogal em estudo, mesmo em posição pretônica, que parece não ser razão de estigma, mas ao considerarmos os índices atribuídos aos sujeitos de nível superior, assim como os do médio, percebemos que o estigma está presente, pois a disparidade é grande entre o não alfabetizado (63\%) e o falante do nível superior (43\%). Assim, chegamos à conclusão de que o falar ribeirinho da Amazônia Tocantina, no que tange à elevação da vogal média posterior, sofre estigma a julgar pelas tendências apontadas pelo programa estatístico. 


\section{REFERÊNCIAS}

ARAÚJO, Marivana \& RODRIGUES, Doriedson. As vogais médias pré-tônicas /e/ e /o/ no português falado no município de Cametá/Ne do Pará - uma abordagem variacionista. Universidade Federal do Pará, 2007.

CAMPOS, Benedita Maria do Socorro Pinto. Alteamento vocálico, das vogais prétônicas do português falado no município de Mocajuba-Pará. (Mestrado em Estudos Linguísticos) - Universidade Federal do Pará, Belém, 2008.

CASSIQUE, Orlando. Menina Bunita Minina ... olhus esverdeados: estudo variacionista da nasalidade vocálica pré-tônica no português de Breves-Pará. (Mestrado em Estudos Linguísticos) - Universidade Federal do Pará, Belém, 2001.

CORREA, Kimberlin; CAMPOS, Benedita Maria do Socorro. Linguagem, estigma e identidade da Amazônia paraense, um exame de base variacionista do alteamento vocálico em posição pretônica no nordeste do Pará. Relatório PIBIC/UFPA, 2018;

DIAS, Marcelo et al. As Vogais Médias Pretônicas no Português Falado nas Ilhas de Belém (PA). In: ARAGÃO, Maria do Socorro Silva de (Org.). Estudos em fonética e fonologia no Brasil. João Pessoa: GT - fonética e Fonologia/ANPOLL, 2008.

GOFFMAN, E. Estigma: notas sobre a manipulação da identidade deteriorada. Rio de Janeiro: Zahar, 1975.

HALL, S. A identidade cultural na pós-modernidade. Rio de Janeiro: DP\& A, 2001. p. 13. Pp.11-12, 2001.

LABOV, William. Modelos sociolinguísticos. Traducción José Miguel Marinas. Madrid: Cátedra, 1983.

RODRIGUES, Doriedson do Socorro. Da zona urbana à rural/entre a tônica e a pretônica: alteamento /o/ > [u] no português falado no município de Cametá/ $/ \mathrm{Ne}$ paraense - uma abordagem variacionista (Mestrado em Estudos Linguísticos) Universidade Federal do Pará, Belém, 2005.

SILVA NETO, Serafim da. Introdução ao estudo da língua portuguesa no Brasil. 4. ed. Rio de Janeiro: Presença, 1977. 